Open Access

\title{
Regulatory compliance as fulfilment of corporate social responsibility: an interpretative textual analysis on sustainability reports of two Chinese listed agribusinesses
}

Xiaorui Wang ${ }^{1,2}$ (1D

\section{Correspondence:}

ray.wangxr@gmail.com

'DRM-MOST, Université

Paris-Dauphine, Place du Maréchal

de Lattre de Tassigny, 75016 Paris,

France

${ }^{2}$ Present Address: 3 Place Saint

Martin, 26200 Montélimar, France

\begin{abstract}
Through a series of interpretative textual analysis on the sustainability related nonfinancial disclosures of two large agribusinesses in the People's Republic of China, this paper intends to reveal how these reports are used to respond to institutional and social pressures, and how the firms are engaged in the struggle to shape the social reality in a way that serves their own interests. The findings indicate that, firstly, the two sets of sustainability reports share a common understanding of "responsibility", which refers to the very basic product quality control. And secondly, they appear to have different perceptions of "stakeholder", which is largely resulted from the different corporate nature. Both the similarities and the differences in the two sets of reports are tightly linked to the broader social and institutional settings in China.
\end{abstract}

Keywords: Agribusiness, China, CSR, Disclosure, Interpretative textual analysis

\section{Background}

The definition of sustainability has evolved over time and entails various interpretations, the essence, however, remains unchanged: To make an entity (regardless a firm or a state) "sustainable" is to strike a balance between attaining its own prosperity and respecting the needs of its environment, or in other words, not to consume resources faster than they can be reproduced, in both social and ecological sense. (Mebratu, 1998; Ostrom \& Dietz, 2002; WCED, 1987) Nowadays, international, national and regional authoritarian institutions have developed measures, especially accounting and reporting schemes that are engaged in increasing transparency and thus in better dealing with environmental and social problems at each level. Meanwhile the firms have also responded to these challenges, driven by multiple motives.

In the academic world, analyses and empirical evidences have been accumulating regarding the "window dressing", or "impression management" nature of firms' sustainability reports ${ }^{1}$ on Corporate Social Responsibility (or CSR reports), the most prevalent form of 'accounting for sustainability' adopted by business both in China and around the world (see Cho et al., 2010, 2015; Lin, 2010; Livesey \& Kearins, 2002 among many

(c) The Author(s). 2017 Open Access This article is distributed under the terms of the Creative Commons Attribution 4.0 International License (http://creativecommons.org/licenses/by/4.0/), which permits unrestricted use, distribution, and reproduction in any medium, provided you give appropriate credit to the original author(s) and the source, provide a link to the Creative Commons license, and indicate if changes were made. 
others). Despite the abundance of literature, only a small part of it focuses on the language employed by individual reports and its significations, and only very few CSRspecialised scholars focus on agriculture, sector of activity where the ancient philosophy of "living in harmony with the universe" first originated (Liu, 2004; Mebratu, 1998; Wu \& Zhang, 2005).

Through a study on discourses used in sustainability reports of two Chinese listed agribusinesses, this paper revisits some classical topics regarding the CSR (notably the question of government regulations and corporate legitimacy) in the Chinese context, and thus contributes to the literature by revealing how government regulation and the broader social context have influenced the CSR reporting, and by identifying some limitations and possible areas of improvement in the current CSR regulatory framework in China. In line with this perspective, several socio-economic factors, notably corporate ownership, regulatory guidelines for CSR reporting, and important public events are addressed later in this paper, as they represent the subjects that have shaped the form and the content of the two sets of reports.

The remainder of this paper is organised as follows: After an introduction of the methodological framework, some general information concerning the two agribusinesses under investigation, as well as that concerning the two sets of reports are presented. What follows is a detailed comparison regarding the discourses in the two sets of reports and their evolution over time. The elements drawn from the analysis are then linked to the socio-political context in China, followed by an analysis with reference to classical CSR theories. And finally some concluding remarks are given in the end.

\section{Methodology and data acquisition}

This paper adopts the methodology inspired notably by Laine's (2009) interpretative textual analysis. The main focus of this study is to observe the way through which corporate sustainability reports are used to respond to institutional and social pressures, and how the firms are engaged in the struggle to shape the social reality in a way that serves their own interests.

The texts under investigation refers to the verbal elements of relevant corporate reports and policy documents, all of which being conceptualised texts in the narrow sense as referring to spoken and written language (Leitch \& Palmer, 2010; MerklDavies et al., 2011). Further, "the social practice" of relevant corporate discourses (Alvesson \& Kärreman, 2000; Leitch \& Palmer, 2010) is also analysed. What to be underlined here is that, in this paper, the social context, or the (potentially) constitutive cultural code that has shaped the social practice of corporate discourses is illuminated by the text, rather than pre-set and then linked to the text (a culturalist approach) (Livesey \& Kearins, 2002). This research strategy in a way explains the structure of this paper: The two firms and their sustainability reports starts from presenting the textual analysis of the sustainability reports where features, milestones, important time points/ slots and so on are spotted; and Social practice: the institutionalisation of corporate discourse interprets these elements in a broader social context, with reference to regulatory measures of authorities and relevant events in society.

Apart from using the method of interpretative textual analysis mentioned above, the comparative case approach is also applied to this study, as the author contrast the two 
firms with different corporate natures and their sustainability reporting practices. As to the choice of firms, namely the New Hope Liuhe Group and the Beidahuang Group (hereinafter "Liuhe" and "Beidahuang"), it is above all because that the two Chinese agribusinesses share some important attributes in common: both large in size and having important market power in their respective product domain, which could to a great extent provide us with some insight concerning the Chinese agribusinesses as a whole. Second, it is also because that their differences in terms of history, culture, image, the impacts of their products on nature and society, and the circumstances in which their reports were produced are tightly linked to the production of their annual sustainability reports. Investigating these elements can therefore allow us to have a better understanding of the complexity of the matter. And third, from a practical point of view, the availability of data also plays a decisive role: The facts that both firms are leading agribusinesses in their respective sector, and both are listed firms in Chinese Stock Exchanges make their financial and non-financial reports publicly available; whilst the high level executives of these two firms accepted to be interviewed by the author, which makes the collection of rather abundant interview data possible.

This paper analyse all the relevant reports of these two firms since the year they officially started issuing sustainability reporting (as it is the case for Liuhe), or started including sustainability related materials in a less formal manner (as it is the case for Beidahuang), till the year of $2014 .^{2}$ All textual materials of corporate reports and policy documents are available on line, complemented by transcripts of spoken materials acquired from telephone and face-to-face interviews led during a field work in China in 2012. The use of interview data is above all because of its additional explanatory power - It allows the acquisition of information that has not been fully disclosed by the firms in written discourses. The data acquired from interviews with these 'spokesmen' of the firms could confirm or contradict the message that their respective firms intend to deliver in written ones open to the public.

The assumption of this paper is that, within a certain geographical and historical scale of a society, the socio-political context greatly influences critical decisions made by organisations. Therefore it is this socio-political context in contemporary China that decides whether, when and how for the Chinese agribusinesses to report on CSR.

\section{Case presentation: The two firms and their sustainability reports Company profile New Hope Liuhe Group}

Liuhe's background is rather ordinary. Built and run by the family of Liu as a private enterprise since 1982, went public in 1998 and completely took over the runner-up firm in Chinese animal feed and livestock sector in 2010, it is the biggest listed group company of animal feed and livestock in China. The relationship between Liuhe and the authorities is also rather ordinary: the firm as economic activity practitioner, whilst the authorities, notably the regional ones, as regulator. A senior executive of one of Lihue's biggest subsidiaries has confirmed, with $95 \%$ of business based on the domestic market and $5 \%$ on export, the recognition of the firm's brand and product among the Chinese natives appears to be extremely important to the firm. ${ }^{3}$ 
As regards the firm's sustainability reporting, in 2009, Liuhe ("New Hope" at the time, until 2011) issued its first stand-alone CSR report alongside its annual report on the year of 2008. As proudly stated in the first CSR report and on its official website, "New Hope ... is the first domestic enterprise in China who publishes annual CSR report". Ever since, Liuhe has kept its promise and been issuing this report so far every year. The guidelines under which the reports were prepared were not clearly defined until 2010. In total, Liuhe has published two reports (2008 \& 2009) without specified guideline, two reports (2010 \& 2011) prepared under the Social responsibility guidelines of listed companies of Shenzhen Stock Exchange (SZSE) with reference to the Social responsibility reporting guidelines for Chinese enterprises of the Chinese Academy of Social Sciences (CASS), and two reports (2012 \& 2013) under guidelines of China Securities Regulatory Commission (CSRC) and the SZSE, with reference to the G3/ G3.1 Guidelines of Global Reporting Initiative (GRI) and the CASS-CSR1.0, which is the formal version of the CASS guidelines of 2010.

\section{The Beidahuang Group}

Compared to its counterpart Liuhe, the case of Beidahuang is a bit unusual, as it has a double identity: It is equally known as the Heilongjiang (province) Land Reclamation Bureau, the concept of which is close to that of municipality. Went public in 2002, It has been the biggest listed agricultural conglomerate that manages the biggest stateowned farm, under direct management of the Ministry of Agriculture. ${ }^{6}$ This firm is actually a unique kind of economic and semi-military governmental organisation that was originally designed by the central authority back in 1950s to effectuate farming activities in regions endowed with severe natural environment. In short, as a high level department director of Beidahuang put it, today, "Beidahuang is essentially an administrative region run as a group company. The organisational structure and the set of leadership are exactly the same for the region and for the firm". According to him, as one of the most important national commodity grain base of the country, the firm does not seem to need to worry about its sales channels, since the State will purchase a good proportion of the harvest every year.

To date, the Beidahuang Group does not provide stand-alone sustainability report. Instead, from 2012, they have started to include three pages of "Active fulfilment of social responsibility" chapter in the Directors' Report of its annual reports (see below). The guideline under which the content is prepared is however not clearly defined, what seems to be relevant is a statement of report preparers: It is stated that this chapter is an achievement of the firm's "social responsibility management system", established in 2012, in compliance with an official "Circular" promulgated by the regulative authorities.

\section{Presentation of the reports}

Based on the guidelines under which the reports were prepared, the structural and textual presentation, the comparison of the two sets of reports in terms of presentation-as well as in terms of their development over time-is summarised in Table 1.

As demonstrated above, whereas the reports of Liuhe show a continuous trend of development, the set of Beidahuang reports appears to be incommensurately underdeveloped. In contrast to Beidahuang's two almost identical sustainability reports since the firm started including them in the annual reports, those of Liuhe's seem to have 
Table 1 Comparison of the two sets of reports

\begin{tabular}{|c|c|c|c|c|c|}
\hline & \multicolumn{3}{|c|}{ New Hope Liuhe Group } & \multicolumn{2}{|c|}{$\begin{array}{l}\text { Beidahuang Group, and Heilongjiang } \\
\text { Land Reclamation Bureau }\end{array}$} \\
\hline Firm feature & \multicolumn{3}{|c|}{$\begin{array}{l}\text { Private enterprise, biggest listed group } \\
\text { company of livestock and animal feed }\end{array}$} & \multicolumn{2}{|c|}{$\begin{array}{l}\text { Biggest agricultural conglomerate } \\
\text { under direct management of MOF, } \\
\text { biggest state-owned farm }\end{array}$} \\
\hline Mandatory report & \multicolumn{3}{|c|}{ Yes, since 2008} & \multicolumn{2}{|c|}{ Yes, since 2012} \\
\hline Stand-alone CSR report & \multicolumn{3}{|c|}{ Yes, since 2008} & \multicolumn{2}{|l|}{ No } \\
\hline Third-party verification & \multicolumn{3}{|l|}{ No } & \multicolumn{2}{|l|}{ No } \\
\hline Volume of the reports & \multicolumn{3}{|c|}{16 (in 2008)-58 (in 2013) pages of full report } & \multicolumn{2}{|c|}{$\begin{array}{l}2-3 \text { pages of a section entitled } \\
\text { "Active fulfilment of social } \\
\text { responsibility" in the annual report }\end{array}$} \\
\hline Stages & 2008-09 & $\begin{array}{l}\text { 2010-11 (Liuhe 2010; } \\
\text { Liuhe 2011) }\end{array}$ & $2012-13$ & 2012 & 2013 \\
\hline Guideline & None & SZSE, CASS & $\begin{array}{l}\text { CSRC, SZSE, GRI, } \\
\text { CASS-CSR1.0 }\end{array}$ & None & None \\
\hline
\end{tabular}

evolved greatly over time, especially in terms of structure. Even though not specified at the beginning in 2008, the reference to the GRI guidelines is already obvious, as the stakeholder focus has been reflected in all the 6 reports of Liuhe's; whilst the guidelines under which Beidahuang prepares its reports have not been clear enough. Moreover, we see that over time, Liuhe's information disclosure has become increasingly well-organised and more equally weighted for all the chapters dedicated to specific stakeholder groups.

Further regarding the evolution of the two series of reports, we also note that the quantified information disclosure has increased. However, the usefulness of this information is uncertain: In both series of reports, there is hardly any information concerning the effectiveness of the numerous measures taken by both firms claimed as "CSR fulfilment". Concrete numbers do have been provided; however almost all of them are in terms of 'input', with hardly any quantified 'output', or results of the measures taken. Since the quantified information disclosure is not mandatory, this phenomenon could be interpreted as either the impact of a certain measure is too difficult (at least too difficult for the firm itself) to describe and measure due to lack of operational standards and measurement, or the report preparers consider that the performance is too poor to present in a sustainability report, since they do not have any obligation clearly defined by laws and regulations to disclose anything in this report that might make the firms appear as if having failed to fulfil any of their responsibilities.

Another similarity is that, whereas both firms have claimed having established an internal social responsibility management system (Liuhe, 2014; Beidahuang, 2013), none of their sustainability reports has passed third-party verification. This is otherwise in accordance to the general practice in China, since as demonstrated in SynTao's well researched annual reports on the current CSR reporting in China, more than 95\% of the sustainability reports released by Chinese listed firms from the period 2008-2013 were not independently audited by a third party (2013, p. 7). This phenomenon could be interpreted again as an investable result of the fact that there is no compulsory requirement from the authorities for this kind of verification. On the other hand however, this is also related to the fact that there are very few, if any, eligible institutions that propose this service; and hardly any uniformed standards, or at least widely accepted guidelines for the third-party institutions to follow when they intend to be engaged in 
sustainability report verification. (Ma, 2014; Shen et al., 2010) This lack of third-party verification is actually linked to the lack of proper measure to show the effectiveness of the 'CSR fulfilment' mentioned earlier. Further improvement in this domain constitutes one of the most needed efforts for Chinese CSR reporting in future, since according to experiences of some multinational corporations, the verification of specialised third-party institutions could not only increase credibility of the reports, but also could serve as measures to better describe effectiveness. (Livesey \& Kearins, 2002, p. 239; cf. SynTao Co., 2013)

As to the writing style, we find that the positive attitude and affirmative tune could be easily spotted in both series of reports, notably for the fact that, in the 6 stand-alone and 2 integrated annual sustainability reports under investigation, there is hardly any difficulty reported regarding the preparation of these reports, such as lack of instrumental and uniformed guidelines, difficulties in terms of quantitative measurement, let alone any critical thinking, such as reflexions on the value conflicts among stakeholders and so on. It seems that overall the introduction of CSR into these firms' reporting practice is without any obstacle, or at least not at all worth disclosing in the reports, which is quite the opposite comparing to what is reported in the Western literature, even in the reports of the most experienced sustainability reporting practitioners like The Body Shop (2012).

The positive attitude is also clearly reflected in terms of wording (for instance "progress and achievement", "active fulfilment", "promotion" and so on in the chapter titles of the reports presented above). What worth noticing at this point is that, for Liuhe, whilst its 2010 report follows its two previous reports using the word "fulfilment" in the title of the second main part, for exactly the same section, its 2011 report changes this word subtly into "practices", a word endowed with more neutrality. Over time, there have been several similar changes of this kind in Liuhe's reports, which suggests that its report preparers have intended to improve their CSR report by means of using less biased words and less affirmative tune to make the reports (look) more rigorous. Meanwhile, Beidahuang continues to prepare the reports in a rather perfunctory manner, without much effort made even in terms of wording.

\section{Comparisons regarding the three main subjects of the reports}

As we zoom in for a more close-up inspection of the content, we could find that on top of the 'good deed only' reporting principle, the information disclosed in both series of reports demonstrates some interesting features that are presented below from three dimensions.

\section{Food safety}

From the years (2009 and 2013 respectively) when both firms started publishing their sustainability reports till 2014, ${ }^{7}$ both firms have dedicated the biggest proportion (around $30-40 \%$ ) of the content to product quality control, and have repeatedly recognised this part of their social responsibility as the most essential one as an agribusiness. For instance, Liuhe considers that

"The firm has always given the highest priority to food safety and always been focusing on quality control from the very beginning of the industrial chain."

(Liuhe, 2009, p. 2) 
And in terms of concrete measures taken, Liuhe further emphasises its efforts on industrial chain management by disclosing detailed and quantified information concerning the significant amounts of investment in equipment, technical experts and other human resources, and states that

"As an agribusiness that involves the biggest and the most scattered farming industrial chain in China, we see ourselves as an industrious 'servant' of the whole producing process, who's engaged in providing a series of reliable services including supplier selection, technical tutorship, quality and drug residue verification and so on, in order to ensure the safety of our food and livestock feed products at every stage of the process." (Liuhe, 2014, p. 14)

Indeed, according to the senior executive interviewed, as a privately run firm that owns very few farms of its own, Liuhe deals with a good number of individual family farms and village-level agricultural cooperatives on top of other suppliers of seedlings, chicks and farm chemicals; and this have no doubt complicated the task of product quality control. This is probably the raison why the report preparers have decided to stress on this issue and to place the firm in a rather humble and powerless position ("servant") instead of picturing the firm as an entity that is fully responsible for its food product (un-)safety, especially when there are rumours circulating concerning the loose quality control of Liuhe's contracted farms. ${ }^{8}$

Beidahuang, on the other hand, addresses this matter from a different angle. It is stated at the beginning of the product quality control section that

"Nowadays the food safety problem gains growing concern nationwide. Beidahuang, as the state farm entitled 'The Big Barn of China', has undoubtedly been paying increasing attention to this subject." (Beidahuang, 2013, p. 21)

Right afterwards, the report preparers enumerate a number of quality verifications their products have passed, and then emphasise that

"We have established a food safety traceability system that closely controls the whole life cycle (species selection, planting, storage, processing and distribution) of our products. We regard our crop fields as the first workshop of production. We plan the producing process of our farms as a whole and we manage the process in a highly standardised and uniformed manner: unique source of seeds, unified arrangement of crop variety, unified funding management, unified planting model, and unified operating standards." ${ }^{9}$ (Ibid.)

As we have noted, the firm's confidence on its product quality seems to be unquestionable, even in the time of food safety crisis where the grain production, Beidahuang's main business, is also under the spotlight. ${ }^{10}$ We note as well that the idea of 'control' is repeatedly demonstrated in the following descriptions of their quality control system ("traceability", "closely control", "plan ... as a whole", "highly standardised and uniformed"). It appears reasonable for the report preparers to stress on the firm's strong controlling power as its biggest strength that proves its product safety: As confirmed 
by the corporate governance section of the annual reports and by the department director of Beidahuang in the interview, as a state-owned farm, Beidahuang does have a much centralised and highly effective control in every domain of its activities; thanks to the centralised distribution of the croplands (directly owned by the firm) in the region, and thanks to its autonomy in terms of administrative status, which avoid the firm from dealing with possible constrains set by regional (notably provincial) governments. In addition, according to the department director interviewed, though equally large in scale, unlike its counterpart Liuhe, Beidahuang's business involves a much shorter industrial chain, where almost every part of the chain is actually a part of the Beidahuang Group and every individual household farmer is an employee of the firm. And it is this direct 'ownership system' that allows such vertical and centralised management and control systems to function.

\section{Natural environment and resources}

The section concerning the natural environment protection and rational use of natural resources constantly occupies the second-most-significant length of the content in both sets of reports. For this subject, both Liuhe and Beidahuang have reported increasingly detailed and quantified information concerning the investments in clean energy and pollution control, and both firms have provided a number of successful cases in their farms and subsidiaries, for instance,

"We are engaged in finding effective solutions to farming pollution problems in order to produce safer food in a cleaner environment. ... A good example is our Xushuidawu hoggery: For the hog manure disposal, we separate the dry hog manure from the wet manure and sell them as farm fertiliser to local farmers at an extremely low price. Meanwhile we invested 30,000 yuan ${ }^{11}$ and built biogas digesters for wet manure treatment. The treated water is used for farmland irrigation. This is a typical example of our efforts both on livestock hygiene and on pollution control" (Liuhe, 2012, p. 22).

"Liuhe is committed to producing environment-friendly, safe and 'green' food. To this end, the firm is engaged in implementing a sustainable development model."

(Liuhe, 2014, p. 49)

"The company has introduced to the farms advanced biotechnologies such as [...]. After 2 years of implementation, the use of these technologies has improved the effectiveness of fertilisers in the soil and thus has reduced the quantity of fertiliser input, degraded the pesticides, fertiliser residue and heavy metals in the soil, and improved the immune system of the crop plants. The wide use of these technologies has greatly reduced the impact of farming activities to the soil and ensured the food product safety of Beidahuang as the national grain base." (Beidahuang, 2014, pp. 20-21)

As shown above, we note that efforts claimed as pollution control and environment conservation are clearly linked to the subject mentioned earlier: food safety. This is not surprising since one salient feature of agribusinesses is the fact that, unlike most firms in other sectors of the economy, agribusinesses have a much tighter link to the natural 
environment, as the quality of their products to a large extent relies on natural environment that conceives the (raw material of) products. This point was otherwise brought up several times by both interviewees in the interviews, during which they both used their firms' environment-friendly practices as a strong argument for the high standards of hygiene and quality control set by their respective firms' in production process. The repeated linkage between environment conservation and food safety made by the report preparers as well as by the interviewees has again showed the priority of convincing the readers about the safety of their products.

\section{Social aspect}

A large variety of information is categorised as reporting the social aspect of the firms' performance. First of all, both firms have devoted considerable length to philanthropic activities. The main subjects are charitable donations that are tightly linked to some major events in society, notably natural disasters of the relevant reporting year. Others involve efforts on social welfare, such as donations to primary school construction in rural districts and organisation of cultural activities. This kind of content occupies on average $20 \%$ of the length in the reports, with nevertheless a visible decline on Liuhe's end: 7 pages over 16 in the 2008 report compared to 9 pages over 58 in 2013. In fact, the tendency of (over-)emphasising charity information is a kind of 'tradition' for the sustainability reports of Chinese firms, especially when comparing with CSR reports of firms in the West (Lin, 2010; SynTao Co., 2013). This is understandable since a firm would naturally intend to communicate this information to embellish the firm's image, particularly when it is expected, or in some cases required to prepare a 'sustainability report' without specific guideline to follow. This phenomenon has reduced the usefulness of the reports and therefore needs to be changed, notably by legislative efforts of the authority (SynTao Co., 2007). In fact, as we have noted regarding the evolution of Liuhe's reports over time, this situation does have been improved alongside the increasingly complete guidelines released by authorities.

Second, apart from philanthropic activities, the two firms report from quite different perspectives regarding the wellbeing of the society: Whilst Beidahuang has focused on the safety and wellbeing of their employees (sections entitled "Safe production" and "Promotion of employment and employee rights protection"), Liuhe seems to have recognised a larger variety of relevant interest groups ("Shareholders and creditors", "Suppliers, customers and consumers" and "Employees"); and the two interviewees confirmed this difference in their respective firms' managerial practice. This phenomenon could well be resulted from the large disparity in terms of form and volume of the two series of reports: Liuhe's stand-alone reports would after all cover more issues compared to Beidahuang's three pages of annual-report-integrated ones. Nevertheless, it also echoes the point presented earlier, which is the different nature and thus the different positioning of the two firms in their business: For Liuhe, a private firm owning very few farms of its own, it does have to maintain rather complex relationships with multiple groups of people, especially those with individual household farmers, since they could be on the one hand its raw material (grain, meat and milk) supplier, and on the other its customer (of livestock feed). We could say that Liuhe's contribution to the wellbeing of the society consists largely of maintaining a harmonious relationship with the farmers. Whilst for Beidahuang, things are much simplified since as the 'owner' of 
all the croplands of the firm's farming activities, the farmers are recognised only as one kind of stakeholders: the employees. Therefore for Beidahuang, taking care of its employees already includes the meaning of enhancing the wellbeing of farmers and rural livelihood at large (Shao et al., 2011). It seems that Beidahuang has to a great extent 'internalised' the social problem thanks to the special nature of the firm.

\section{Comments}

After a review of the detailed disclosure in the two series of reports, we note that first, the different corporate nature of the two firms has greatly affected their respective positioning in the business, as well as their attitude towards sustainability management and reporting. Second, the composition of stakeholder group for the two firms is different, which is again linked to their different corporate nature. And third, if we relate the three aspects of information disclosed in the reports to the fundamental conceptual framework of sustainability reporting: the famous 'Triple bottom line' (TBL, cf. Elkington, 1997), it seems that the central part of all the reports-that is "food safety"-represents the financial dimension of sustainability (rather than the environmental and social ones); and that the 'bottom lines' have been set quite low in the sense that producing safe food is recognised as the most essential competence that guarantees the firm's economic viability and ethical values. This is very likely due to the vulnerable nature of the agricultural industry itself in terms of its comparatively low profitability (da Silva et al., 2009; Gao, 2006; Saporta, 2011), and due to the broader socio-political context in China as well.

Still, in the context where companies that disclose CSR reports have only occupied less than $25 \%$ of the total number of Chinese listed companies over the past decade, ${ }^{12}$ Liuhe and Beidahuang represent already the 'good examples'. The next section discusses the evolution of CSR reporting with reference to that of social settings in China, and deciphers the interplay of these two elements.

\section{Social practice: the institutionalisation of corporate discourse}

As mentioned earlier, in this study, the social context under investigation is illuminated by the text. This section therefore goes deeper into the investigation of three subjects (food safety, natural environment and resources, and social aspect) evoked above, by looking at the social pressure that these corporate discourses look to response. Interview data are used in this part of the study both as evidence from the terrain and as indicative factors that reorient the investigation depending on cases.

The increasing food safety problems in China have greatly affected the two firms under discussion and the policy making of the authorities as well. In 2008, the 'melamine scandal' bursted out in Chinese milk industry: An enormous quantity of milk products, infant formulas and other food materials and components adulterated with melamine was spotted in the market. Infants who had taken this kind of formula milk could develop kidney stones and if affected seriously, the consequences could be fatal (Noronha et al., 2013). This event is probably the most shocking product quality scandal that ever existed in China, not only because the damage was bad and this time it was the newly born and children who were the main victims, but also for the fact that the most exposed firm was Sanlu, a well-known group company specialised in dairy product. The social consequences of this event are extremely extensive, especially in terms of public confidence in food products in general. This pressure from the public is 
seen as the main accelerator of the Chinese government's efforts on promoting sustainability reporting of the firms (CASS, 2009; Noronha et al., 2013; Shen, 2009; Wu, 2008). Nevertheless, the scandals in the food industry did not stop making their appearance since then; and the questioning voice of Chinese people has been even louder. On 18 December 2012, an exposé on CCTV, China's national broadcaster, reported that poultry product suppliers (Liuhe among the major ones) to KFC and McDonald's were doing force feeding and were stuffing their chickens with excessive antibiotics. In May 2013, a large quantity of rice containing excessive levels of cadmium (a kind of heavy metal) was found in markets notably in the southern part of China, which suggested severe heavy metal pollution of China's rice crops produced in the south.

Facing these challenges, the firms have made their moves, and as it is usually the case, much quicker than the government. It was in April 2009, less than 1 year after the melamine scandal that Liuhe took the initiative and released its first annual standalone CSR report. ${ }^{13}$ Directly (though slightly) affected by the scandal since the firm has several small scale subsidiaries producing dairy products, Liuhe claimed that all of their products "passed strict inspection conducted by the national authorities and no melamine was detected"; and that in future the firm will "strengthen the quality control and continue to perform strict milk quality control" (Liuhe, 2009, p. 2).

Similarly, in the 2012 CSR report, the 'fast-growing chicken' issue was raised. As the firm that was directly exposed by CCTV this time, Liuhe claimed in the report that "right after seeing the exposé, an investigation team composed by top executives of the firm rushed to the farms in question, sealed all inventories of raw materials and products, and thoroughly checked the quality control system on site". Afterwards the firm "paid the contracted local farmers anyway in order to ensure their livelihood". The firm expressed "the deepest apologies to consumers" and promised "complete rectification" (Liuhe, 2013, p. 36).

We note that regarding both events in which the firm were involved, Liuhe's reports address these issues in a rather direct manner, in the hope of rescuing the firm's image, either by 'pleading innocence' (as in the former case) or by showing prompt action of damage control and caring gestures (as in the latter). In fact, as raised several time by Liuhe's senior executive interviewed, every time when the firm is affected by this kind of scandalous events, they do have a strong feeling of "powerlessness", as put by the interviewee, in controlling product quality in scattered and complicated industrial chains. If we look at the trajectory of Liuhe's reporting development, we can find that the years of the firm's 'milestone' reports correspond perfectly to the time points of food safety crises in China, which to a great extant proves that the main motivation for Liuhe to begin and to continue their sustainability reporting practice is to rescue the corporate image. This observation echoes the findings of Cho and Patten (2007) that firms use relevant disclosures as tools of legitimacy.

As to Beidahuang, the national grain base situated in the far north and specialised notably in rice production, the rice scandal in the southern provinces does not seem to have affected the firm's sustainability reports at all. The reports 'naturally' do not mention anything concerning this event since the firm's image has not at all been damaged. Rather, after the burst-out of this scandal, Beidahuang's rice has gained increasing popularity, especially in the south, since the consumers in the southern provinces who had been accustomed to local rice for decades are now obligated to purchase rice 
produced in the north due to safety concerns. As a matter of fact, this scandal has to a large extent acted as a free advertisement for Beidahuang. Nevertheless, the report preparers of Beidahuang have still chosen to lay stress on its effective product quality control in order to reinforce the firm's good image.

Meanwhile, for the Chinese government, the food safety scandals reflect only one facet of problematic issues currently confronting the country, the other major concerns being natural environment degradation and social security shortfall, which echo the other two important subjects of the two sets of reports. Facing the questioning voices of the society, the central government seems to have intended to assimilate the stakeholder theory and the idea of shared social responsibility, ideology advocated recently notably by occidental capitalist countries (Wang \& Juslin, 2011): Since 2000s, the authorities have been delivering an important message through various channels, emphasising that that problems in product quality control, natural environment protection and human wellbeing at large cannot be solved if relying solely on supervision and regulation of the government, and that the whole society, especially the firms should take their part of responsibility and communicate their efforts, or the lack of efforts, on the matter (CASS, 2009; He et al., 2013; Lin, 2010).

To do so, the government has started to take a series of regulatory measures, notably within the realm of stock exchanges, in order to encourage sustainability reporting of listed firms (Noronha et al., 2013). In December 2008, the Shanghai Stock Exchange (SSE) issued the Circular about Disclosing Social Responsibility Reports and Internal Control Self-Evaluation Reports for Listed Companies in 2008. This document required three types of listed companies, including those issuing A and H shares, those in the corporate governance sector and those in the financial industry to disclose CSR reports alongside their annual reports, and also encouraged other companies to follow this practice voluntarily. In the same year, the SZSE issued the Circular about Disclosing Annual Reports of 2008 for Listed Companies, which required listed companies constituting the "SZSE 100 Index" (which includes Liuhe) to report on their CSR practices and also encouraged other companies to follow this practice voluntarily. In 2012, another Circular entitled Implementation of a standard internal control system in main board listed companies within the year of 2012 was released by the Ministry of Finance, which required all firms listed in the main board of SSE (which includes Beidahuang this time) to conduct a pilot test of social responsibility reporting, if have not been practicing this kind of reporting already.

In these documents, it is repeatedly stated that the promulgation of CSR related regulations are for the purpose of concretising the 'caring' for stakeholders, concept imported from the West. For instance, in the SSE Circular in May listed above, the text starts with the paragraph as follows:

"In order to advocate for active commitment of listed companies to fulfil social responsibility, to concretise the concepts of 'sustainable development' and 'scientific perspective of development', to promote the caring for corporate stakeholders including employees, creditors, customers, consumers and the community stakeholders whilst concentrating on the firm's own economic interests, we make the following requirements to companies listed in SSE regarding the fulfilment of CSR." ${ }^{\text {"14 }}$ 
With the Circulars, Guidelines as well as a series of laws and regulatory documents issued from various authoritarian institutions, the Chinese government plays an important role in guiding the discourse of sustainability reporting of Chinese firms. However, The lack of widely agreed conception of sustainability and CSR, and the lack of uniformed and mandatory standards have resulted in the highly disparate reporting practice among the firms: As demonstrated in the previous sections, even though both Liuhe and Beidahuang are required to prepare sustainability reports by authorities, their reports are quite different in terms of volume, form and content organisation; whilst they are all short of quantified information provided under specific standards, and therefore lack comparability and usefulness.

Figure 1 summarises the sequence of social events and the two firms reporting practices in order to make the timeline clearer. As we can see, this timeline echoes the assumption of this paper. Three food safety scandals (among many others) mentioned above are listed in the first line whilst the policies are listed in the second, the colour of the asterisks on top of each event and each policy matches the font colour of the firm implied. As reported by national and international medias (cf. Foster, 2011), it is precisely because of these events that people started to seriously question the business ethics of the whole food industry and the proper function of regulatory authorities. This pressure from the public is widely seen as the main accelerator of the Chinese government's efforts on promoting sustainability reporting of the firms, and in turn as the main reason that has driven the agribusinesses to conduct this kind of reporting.

\section{Rethinking the above cases with reference to CSR theories}

According to positive accounting theory, a firm is seen as "a nexus of contracts"-in the strict sense of the word-and therefore is supposed to use accounting and reporting as tools to facilitate the formation and the performance of the contracts (Coase, 1937). Further regarding the CSR of a firm, the stakeholder theory seems to be frequently mentioned: There is also a "social contract" between the firm and each one of its stakeholders (Roberts, 1992; Ullmann, 1985). Since the contractual relationships recognised by Coase are extended to those with stakeholders by the social contracts, a firm is supposed to use sustainability reports as a tool to communicate relevant information to legitimise its existence and its activities, for the purpose of maintaining these relationships. Sustainability reports on a firm's CSR are thus produced to address social and environmental issues that a firm faces. However, due to the fact that these issues are deeply embedded in a broader institutional context, it seems inevitable that we also need to examine the question of CSR through the lens of political economy.

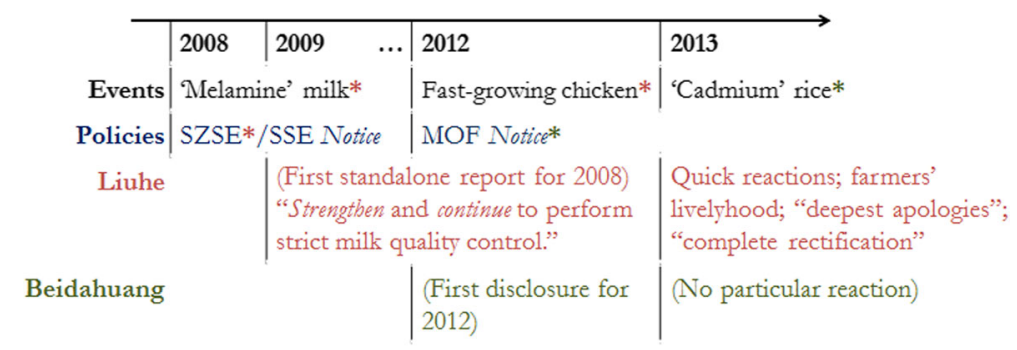

Fig. 1 Sequence of events and the two firms reporting practices 
In the context of China's spectacular economic growth and the accompanying environmental and social crises, the two agribusinesses under investigation do not seem to draw enormous attention, since they are absolutely not among the firms delivering the highest economic performance, nor among the ones acting the most poorly in terms of environment conservation and labour protection. According to the textual analysis of their reports, what seems to be the top priority for these two firms, and also very likely for the whole food industry in China, is the food safety, the very basic corporate responsibility for an agribusiness which is not supposed to occupy such overly significant length in their sustainability reports for so many years. These findings echo perfectly those of Laine's (2009): It is pointed out in his case study that the transitions in the firm's environmental disclosures coincide with changes in the social and institutional context. In our case, the author takes one step further and confirms that, it is the context of food 'unsafety' in China that has shaped the form of Chinese agribusinesses' CSR reports. This point is otherwise also implicitly suggested by the high-level executives interviewed.

After an analysis of the discourses in these sustainability reports, we find that through the texts, the firms are engaged in constructing a reality (only) serving the purpose of improving corporate image, rather than report substantial and well quantified information against a set of scientific thresholds set by relevant authorities: On the one hand, they do report the sustainability related issues under the pressure from the authorities and the public, nevertheless only reporting the 'bright side', and in a less rigorous manner; on the other, they would still choose to emphasise what they consider as worth reporting for the firms-that is their product safety, over many other issues that are equally important to the society. These findings echo those of Cho and Patten (2007), Cho et al. (2015), Colleoni (2013), Farache and Perks (2010), Zhao (2012) and many others, who argue that in general firms use environmental disclosures as tools to respond to public pressure, and thus to create or maintain their legitimacy in the eyes of the society. Though, as we can notice in the two sets of reports, the disclosed information is hardly 'informative' and therefore hardly fulfils its function of 'legitimising'.

This failure is to be explained with reference to its broader context. The fact that firms produce CSR reports for the betterment of corporate image per se has nothing wrong. What appears to be a true concern is that the content of these reports serves only this purpose. The non-disclosure of useful quantified information regarding the firms' environmental and social responsibilities suggests that, firms do not voluntarily provide information beyond their specific administrative obligation regarding its CSR. Yet this disclosure is expected by the (potential) investors as they would need detailed and quantified information to evaluate rigorously the environmental impact of the firms, and especially that of the agribusinesses in our case of which the profitability is so closely linked to their natural environment. This disclosure is also likely to be expected by governments and general public due to the fact that China has now entered an era when environmental and social sustainability constitutes a central concern for almost every sector of the economy and for livelihood of every individual.

Further regarding the sustainability reporting practice of the two firms, we note that, whilst the private firm Liuhe deliberately 'humbles' itself in its CSR narratives, the state-owned firm Beidahuang tends to convince its audience of its trustworthiness in CSR issues by underlining its status of quasi-governmental institution. What could be 
deduced is that for the two agribusinesses under investigation, no matter if it is the problem of corporate product quality, environment protection, or social relations faced by firms, it has always been the State that is designated as the entity to take main responsibility. Despite the drastically different style as well as different 'degree' of enthusiasm shown in their reports, the motives of Liuhe and Beidahunag to start their sustainability reporting practice appear to be the same - that is regulatory compliance (because neither of them voluntarily started this practice before they were required to produce CSR reports by authorities ${ }^{15}$ ). These phenomena suggest that unlike its counterpart in the West, in China, the development of CSR reporting is above all a state-led initiative (Zhao, 2012).

These special characteristics of CSR in China seem to be in contradiction with contemporary business ethics of private businesses nowadays in the West, where the State rolls back and the firms are increasingly put forward to assume their social responsibility (Gray, 2007). Regarding this point, what Ms C (Liuhe) says in the interview might represent the voices of most businesses in China:

"The standpoint of the government and that of the firms are definitely different. What the firms need to do is to achieve maximum benefits within the scope of government regulations; and what the government needs to do is to make this regulatory and supervising systems work. There must be such a clear division of responsibility."

Clearly, It is the classical 'nature of the firm' identified by Coase that is referred to by Ms C. Based on this notion, the Chinese agribusinesses' high degree of dependence on the State to fulfil the three dimensions of corporate responsibilities presented earlier appears to be more understandable: Given the multiple restrictions exerted throughout the industrial chain and the nature of low profitability that characterises the Chinese agriculture sector, the mere compliance with laws and regulations already takes great efforts to be attained. In the context where economic viability is paramount, it appears reasonable for the Chinese agribusinesses to focus solely on profit-maximisation, whilst guaranteeing the firm's full compliance with laws and regulations as having fulfilled its share of 'social responsibility'.

Still, the drastically different attitude of these two firms regarding CSR reporting and their incentives behind suggest that, the adoption of sustainability reporting for Chinese firms is endowed with another dimension of the problem, which is the ownership structure of the firms. This finding again demonstrates the importance of institutionalcontext-based analysis in understanding the CSR reporting practices of specific firms.

\section{Conclusions}

In all, what we can draw from the analysis of this paper is in accordance with the diagnosis made by Adams (2001), Adams et al. (2004) and Synnestvedt (2001) more than 10 years ago regarding the situation in the West: While there is an increased volume of disclosure, there are no parallel gains in their quality or the level of accountability discharged, which calls for greater legislation efforts, and for the so called "context-based sustainability management" (McElroy \& Engelen, 2011). Though having been repeatedly stressed over time, the lack of concrete measurement in scientific terms is still prominent (Peterson, 1997, p.22, in Livesey \& Kearins, 2002). 
Based on the regulatory measures taken by relevant authorities of various departments and levels, we note that the intention of the Chinese government to promote the mainstream 'western style' CSR reporting is obvious. The inclusion of firms for mandatory reporting has been expanded and the guidelines have been increasingly detailed and informative. However, to date, there are still no mandatory rules, especially those for concrete measurements of performance, but only guidelines that generally define the content of the report. Further, there is still lack of third-party verification and pressure groups that are engaged in this matter. These factors leave too much liberty to the firms when preparing their reports, and therefore reduce the comparability among the reports and their usefulness. As a state-led initiative, the sustainability reporting practice in China is expected to implement-and does have the potential to implement-more detailed and legislated standards made according to scientifically fixed thresholds, which is probably the most effective way that sustainability reports could genuinely contribute to sustainability of an economy. More observation in future would be needed in order to better judge if the measures taken by the Chinese government are mainly for the purpose of shirking its proper responsibilities as supervisor and regulator of economic activities, or if they are genuine efforts on promoting sustainability and on pursuing a 'harmonious society' through innovative approaches imported from the West.

\section{Endnotes}

${ }^{1}$ In this paper, the term "sustainability report" refers to all sustainability-related nonfinancial reports, which could take (but not exhaustively) the forms of stand-alone "CSR report", "Corporate Environmental Report", "Environment, Health and Safety Report" as well as integrated financial and non-financial annual reports. (KPMG, 2005; SynTao Co 2007)

${ }^{2}$ Here the years mentioned refer to the year of issuing rather than the year reported.

${ }^{3}$ Information also available on the firm's website http://www.newhopeagri.com/ (Last consulted 24/10/2015).

${ }^{4}$ Different from the one mentioned earlier, the official website consulted here is http://www.newhopegroup.com/, the one before the 2010 acquisition. (Last consulted 24/10/2015)

${ }^{5}$ Though this is not exactly true, as a number of other firms, both private and state-owned, had already started publishing their CSR reports earlier than Liuhe (New Hope).

${ }^{6}$ Information acquired from the firm's official website: www.hacl.cn/ (Last consulted 24/10/2015) and its 2007 annual report.

${ }^{7}$ Idem. as footnote 2 .

${ }^{8}$ See more in the article entitled "New Hope Liuhe's extensive expansion: The socalled 'company + farmers' model is only a piece of meaningless paper?" on the National Business Daily website, available at http://www.nbd.com.cn/articles/2013-01-22/ 708997.html, last consulted on 14/12/2015.

${ }^{9}$ Also stated on the firm's website, available at http://www.china-bdh.com/Item/ Show.asp? $\mathrm{m}=1 \& \mathrm{~d}=1606$, last consulted on 14/12/2015.

${ }^{10}$ It refers to the 2011 heavy metal polluted rice scandal. See more in Social practice: the institutionalisation of corporate discourse.

${ }^{11} 1$ euro $=7$ yuan (Renminbi) approximately. 
${ }^{12}$ Information available at http://money.people.com.cn/stock/n1/2016/0824/c6781528661814.html, last consulted on 3/10/2016.

${ }^{13}$ It's worth noting that, even though Liuhe was required to report on CSR by authorities (since it started to be covered in the scope of mandatory CSR reporting scheme ("SZSE 100 Index", see below) set by the stock exchange where it is listed), there was no obligation for Liuhe to issue a full stand-alone CSR reports. Or to put it in simple terms, Liuhe could have integrated a short paragraph regarding the CSR just like what Beidahuang had done.

${ }^{14}$ Available at https://biz.sse.com.cn/cs/zhs/xxfw/flgz/rules/sserules/sseruler20080514a.htm, last consulted on 12/12/2015.

${ }^{15}$ According to different legislative documents mentioned earlier, both firms could have chosen to start this practice at any moment (before 2006 as 'voluntary' reporting, after 2006 as 'encouraged' practice of reporting, or as what they have done, after 2008 as 'mandatory' reporting).

Competing interests

The author declares that she has no competing interests.

Received: 25 November 2016 Accepted: 22 February 2017

Published: 14 March 2017

\section{References}

Adams, CA (2001). A critique of reporting on ethical, social and environmental issues: the case of ICl. Presented at the Third Asia Pacific Interdisciplinary Research in Accounting Conference, Adelaide, Australia.

Adams CA, Frost G, Webber W (2004) Triple bottom line: a review of the literature. In: Adrian H, Richardson J (eds) The triple bottom line: does It All Add Up. London; Sterling, VA: Routledge

Alvesson M, Kärreman D (2000) Varieties of discourse: on the study of organizations through discourse analysis. Hum Relat 53:1125-1149

Beidahuang (2013) Heilongjiang Beidahuang Agriculture Co., Ltd. (600598) 2012 Annual Report.

Beidahuang (2014) Heilongjiang Beidahuang Agriculture Co., Ltd. (600598) 2013 Annual Report.

Chinese Academy of Social Sciences (CASS) (2009) Social responsibility reporting guidelines for Chinese enterprises (CASS-CSR 1.0). Economic Management Press

Cho CH, Patten DM (2007) The role of environmental disclosures as tools of legitimacy: a research note. Acc Organ Soc 32(7-8):639-647

Cho CH, Roberts RW, Patten DM (2010) The language of US corporate environmental disclosure. Acc Organ Soc 35(4): 431-443

Cho CH, Laine M, Roberts RW, Rodrigue M (2015) Organized hypocrisy, organizational façades, and sustainability reporting. Acc Organ Soc 40:78-94

Coase RH (1937) The nature of the firm. Economica 4(16):386-405

Colleoni E (2013) CSR communication strategies for organizational legitimacy in social media. Corp Commun Int J 18(2): $228-248$

da Silva CA, Baker D, Shepherd AW, Jenane C, Miranda-da-Cruz S (2009) Agro-industries for Development (The Food and Agriculture Organization of the United Nations and The United Nations Industrial Development Organization by arrangement with $C A B$ International)

Elkington J (1997) Cannibals with forks: the triple bottom line of 21st century business. Capstone Publishing, Oxford

Farache F, Perks KJ (2010) CSR advertisements: a legitimacy tool? Corp Commun Int J 15(3):235-248

Foster P (2011) Top 10 Chinese food scandals., Retrieved 15 February 2017, from http://www.telegraph.co.uk/news/ worldnews/asia/china/8476080/Top-10-Chinese-Food-Scandals.html

Gao F. (2006). The inferiority of agriculture in China: basis, connotation and ways of transformation. Social Sciences inYunnan 3.

Gray R (2007) Taking a long view on what we now know about social and environmental accountability and reporting. Issues Soc Environ Account 1(2):169-198

He X, Xiao T, Zhu H (2013) Ownership structure, institutional environment and the economic consequences of corporate social responsibility information disclosure: evidence from analysts' earnings forecasts. Chin Account Finance Rev 15(2):60-130

KPMG (2005) The state of sustainability reporting in Australia 2005

Laine M (2009) Ensuring legitimacy through rhetorical changes?: A longitudinal interpretation of the environmental disclosures of a leading Finnish chemical company. Account Audit Account J 22(7):1029-1054, https://doi.org/10. $1108 / 09513570910987367$

Leitch S, Palmer I (2010) Analysing texts in context: current practices and new protocols for critical discourse analysis in organization studies. J Manag Stud 47(6):1194-1212

Lin L (2010) Corporate Social Responsibility in China: window dressing or structural change? Berkeley J Int Law 28(1):3

Liu H (2004) The thought of Confucian agriculture management before the Qin dynasty. Qilu J 1:58-60

Liuhe (2009) Sichuan New Hope Agribusiness Co., Ltd. 2008 Corporate Social Responsibility Report. 
Liuhe (2010) Sichuan New Hope Agribusiness Co., Ltd. 2009 Corporate Social Responsibility Report. Liuhe (2011) Sichuan New Hope Agribusiness Co., Ltd. 2010 Corporate Social Responsibility Report.

Liuhe (2012) New Hope Liuhe Agribusiness Co., Ltd. 2011 Corporate Social Responsibility Report.

Liuhe (2013) New Hope Liuhe Agribusiness Co., Ltd. 2012 Corporate Social Responsibility Report.

Liuhe (2014) New Hope Liuhe Agribusiness Co., Ltd. 2013 Corporate Social Responsibility Report.

Livesey SM, Kearins K (2002) Transparent and caring corporations? A study of sustainability reports by the body shop and royal Dutch/shell. Organ Environ 15(3):233-258

Ma Y. (2014) Research on the verification system of Corporate Social Responsibility Report. Modern Economic Information 4

McElroy MW, van Engelen JML (2011) Corporate sustainability management: the Art and science of managing Nonfinancial performance. Routledge, London, New York

Mebratu D (1998) Sustainability and sustainable development: historical and conceptual review. Environ Impact Assess Rev 18(6):493-520

Merkl-Davies DM, Brennan NM, Vourvachis P (2011) Text analysis methodologies in corporate narrative reporting research. University of St. Andrews, Scotland

Noronha C, Tou S, Cynthia MI, Guan JJ (2013) Corporate social responsibility reporting in China: an overview and comparison with major trends. Corp Soc Responsib Environ Manag 20:29-42

Ostrom E, Dietz T (2002) The drama of the commons. National Academies Press, Washington, DC

Peterson TR (1997) Sharing the earth: the rhetoric of sustainable development. University of South Carolina Press, Columbia

Roberts RW (1992) Determinants of corporate social responsibility disclosure: an application of stakeholder theory. Acc Organ Soc 17:595-612

Saporta I (2011) The Black Book of Agriculture Activities: How they kill our farmers, our health and the environment (Le livre noir de l'agriculture: Comment on assassine nos paysans, notre santé et l'environnement) (Fayard)

Shao W, Zhao Z and Zhang L. (2011) "Six unification" created the major success of Beidahuang. China Sate Farms 10.

Shen J. (2009). Towards deeper green: trace back the corporate social responsibility through the supply chain. 21st Century World Business Herald 28.

Shen H, Wan T, Yang S (2010) Evaluation of status quo of Chinese corporate social responsibility report. Audit Econ Res 6:68-74

Synnestvedt T (2001) Debates over environmental information to stakeholders as a policy instrument. Eco Manag Auditing 8(3):165-178

SynTao Co (2007) A journey to discover values 2007: study of CSR reporting in China

SynTao Co (2013) A journey to discover values: study of CSR reporting in China from 2012 to 2013

The World Commission on Environment and Development (WCED) (1987) Our common future: the world commission on environment and development. Oxford University Press, Oxford

Ullmann AA (1985) Data in search of a theory: a critical examination of the relationships among social performance, social disclosure, and economic performance of U.S. Firms. Acad Manag Rev 10(3):540-557

Wang L, Juslin $H$ (2011) The effects of value on the perception of corporate social responsibility implementation: a study of Chinese youth. Corp Soc Responsib Environ Manag 18(4):246-262, https://doi.org/10.1002/csr.250

Wu H. (2008) Corporate social responsibility seeks its way in China. Science and Technologies Daily 11.

Wu J, Zhang W (2005) The Pre-Qin era Confucian philosophy on agriculture and its significance. Agric Archaeology 1: 223-229

Zhao M (2012) CSR-based political legitimacy strategy: managing the state by doing good in China and Russia. J Bus Ethics 111(4):439-460

\section{Submit your manuscript to a SpringerOpen ${ }^{\circ}$ journal and benefit from:}

- Convenient online submission

- Rigorous peer review

- Immediate publication on acceptance

- Open access: articles freely available online

- High visibility within the field

- Retaining the copyright to your article

Submit your next manuscript at $>$ springeropen.com 